\title{
$\Rightarrow$ GENETICS
}

\section{New insights into Turner syndrome}

Turner syndrome, which results from the complete or partial loss of an $\mathrm{X}$ chromosome, affects 1 in every 2,500 female live births. The condition is associated with a range of morbidities including hypothyroidism, diabetes mellitus and osteoporosis. New research describes novel phenotypic differences between 5 common forms of Turner syndrome as defined by their karyotype.

The present study is part of The Turner Syndrome Life Course Project, which was established in 2014 to document medical outcomes and life experiences of women with Turner syndrome. The cohort of over 780 women is one of the largest data sets of women with the condition. "Owing to the size of our cohort, we were able to focus on the [rarer] forms of Turner syndrome," explains Antoinette Cameron-Pimblett, corresponding author on the study. "We found that patients with a ring $X$ chromosome (45,X/46,X,r(X); $7.3 \%$ of participants) were more likely to have features of the metabolic syndrome characterized by elevated liver enzymes and $\mathrm{HbA}_{1 \mathrm{c}}$ than patients with the classical karyotype (45,X; $41.6 \%$ of participants)."

In addition, the authors report that Turner syndrome caused by $\mathrm{X}$ chromosome mosaicism with a Y chromosome (45,X/46,XY; $10.7 \%$ of participants) is associated with a decreased incidence of thyroid disease and hearing loss. These data indicate that, as it has been observed in the general population, the $\mathrm{Y}$ chromosome in Turner syndrome could be protective against autoimmunity.

The authors now plan to explore the association between diabetes mellitus and $X$ chromosome abnormalities in Turner syndrome. "We believe that the $\mathrm{X}$ chromosome has more secrets to reveal with regards to its contribution to sex-related health risks and that studying women with Turner syndrome will lead to new insights."

\section{Alan Morris}

ORIGINAL ARTICLE Cameron-Pimblett, A. et al. The Turner Syndrome Life Course Project: karyotype-phenotype analyses across the lifespan. Clin. Endocrinol. http://dx.doi.org/10.1111/ cen.13394 (2017) 